\title{
Borderline Ovarian Serous Papillary Cystic Tumor
}

National Cancer Institute

\section{Source}

National Cancer Institute. Borderline Ovarian Serous Papillary Cystic Tumor. NCI

Thesaurus. Code C7271.

A neoplasm of low malignant potential arising from the ovary. It is characterized by the presence of papillary proliferations of atypical serous epithelial cells and a cystic component. There is no evidence of stromal invasion. 